\title{
Predictors of common femoral artery access site complications in patients on oral anticoagulants and undergoing a coronary procedure
}

This article was published in the following Dove Press journal:

Therapeutics and Clinical Risk Management

30 March 2017

Number of times this article has been viewed

\author{
Nicolas W Shammas ${ }^{1,2}$ \\ Gail A Shammas' \\ Susan Jones-Miller ${ }^{1,2}$ \\ Mileah Rose Gumpert ${ }^{\prime}$ \\ Miranda Jade Gumpert ${ }^{1}$ \\ Christine Harb' \\ Majid Z Chammas' \\ W John Shammas' \\ Rommy A Khalafallah' \\ Amy Barzgari' \\ Bassel Bou Dargham' \\ Ghassan E Daher' \\ Rayan Jo Rachwan' \\ Andrew N Shammas' \\ 'Midwest Cardiovascular Research \\ Foundation, ${ }^{2}$ Cardiology Division, \\ Genesis Heart Institute, Davenport, \\ IA, USA
}

Background: It is unclear whether patients on oral anticoagulants (OAC) undergoing a procedure using common femoral artery access have higher adverse events when compared to patients who are not anticoagulated at the time of the procedure.

Methods: We retrospectively reviewed data from consecutive patients who underwent a cardiac procedure at a tertiary medical center. Patients were considered (group A) fully or partially anticoagulated if they had an international normalized ratio (INR) $\geq 1.6$ on the day of the procedure or were on warfarin or new OAC within $48 \mathrm{~h}$ and $24 \mathrm{~h}$ of the procedure, respectively. The nonanticoagulated group (group B) had an INR $<1.6$ or had stopped their warfarin and new $\mathrm{OAC}>48 \mathrm{~h}$ and $>24 \mathrm{~h}$ preprocedure, respectively. The index primary end point of the study was defined as the composite end point of major bleeding, vascular complications, or cardiovascular-related death during index hospitalization. The 30-day primary end point was defined as the occurrence of the index primary end point and up to 30 days postprocedure.

Results: A total of 779 patients were included in this study. Of these patients, 27 (3.5\%) patients were in group A. The index primary end point was met in $11 / 779$ (1.4\%) patients. The 30 -day primary composite end point was met in 18/779 (2.3\%) patients. There was no difference in the primary end point at index between group A (1/27 [3.7\%]) and group B (10/752 [1.3\%]; $P=0.3155)$ and no difference in the 30 -day primary composite end point between group A $(2 / 27$ [7.4\%]) and group B (16/752 [2.1\%]; $P=0.1313)$. Multivariable analysis showed that a low creatinine clearance (odds ratio $[\mathrm{OR}]=0.56 ; P=0.0200)$ and underweight patients $(<60 \mathrm{~kg}$; $\mathrm{OR}=3.94 ; P=0.0300$ ) were independent predictors of the 30-day primary composite end point but not oral anticoagulation $(P=0.1500)$.

Conclusion: Patients on OAC did not have higher 30-day major adverse events than those who were not anticoagulated at index procedure.

Keywords: access site, common femoral artery, complications, oral anticoagulant

\section{Introduction}

Femoral artery access remains the most commonly used arterial access during coronary angiography and intervention despite an increase in radial procedures. ${ }^{1,2}$ Femoral access complications remain infrequent, ranging from $<1 \%$ to $17 \%$ of procedures. ${ }^{3-7}$ It is not uncommon to see patients presenting to the cardiac catheterization laboratory on oral anticoagulant (OAC) fully or partially anticoagulated and undergoing common femoral artery (CFA) access. ${ }^{8}$ Several new OAC (NOACs; oral Xa and thrombin inhibitors) have emerged within the past 3-6 years and are now an alternative to warfarin in treating patients with nonvalvular atrial fibrillation or venous thromboembolic
Correspondence: Nicolas W Shammas Midwest Cardiovascular Research Foundation, 1622 E Lombard Street, Davenport, IA 52803, USA

Tel + I 5633200263

Email shammas@mchsi.com 
disease. ${ }^{9}$ Some data suggest that coronary procedures can be performed safely with uninterrupted OAC at the time of the index procedure. ${ }^{10}$

In this study, we investigated whether orally anticoagulated patients have a higher risk of femoral access site complications when compared to patients who are not anticoagulated with OAC during coronary procedures.

\section{Methods}

We retrospectively reviewed data from 779 consecutive patients who underwent a cardiac procedure (diagnostic or interventional) at a tertiary medical center. Patients were identified from the cardiac catheterization procedural log. Medical records were reviewed by dedicated research assistants, and data entry was audited by a Clinical Research Associate. The study was approved by the Genesis Health System Institutional Review Board at the medical center. Informed consent by patients to review their medical records was waived by the same institutional review board due to the retrospective nature of the study and the large number of patients included that made it impractical or impossible to obtain informed consent from patients. All investigators signed a patient confidentiality agreement with the medical center.

Patients were considered (group A) fully or partially anticoagulated if they had an international normalized ratio (INR) $\geq 1.6$ on the day of the procedure or were on warfarin or NOAC within $48 \mathrm{~h}$ and $24 \mathrm{~h}$ of the procedure, respectively. The nonanticoagulated group (group B) had an INR $<1.6$ or have stopped their warfarin and NOAC $>48 \mathrm{~h}$ and $>24 \mathrm{~h}$ preprocedure, respectively. Non-CFA and bilateral CFA accesses were excluded. Radial procedures were excluded as they are performed infrequently in our medical center.

The index primary end point of the study was defined as the composite end point of major bleeding, vascular complications (arteriovenous (AV) fistula or pseudoaneurysm), or cardiovascular death during index hospitalization. The 30-day primary end point was defined as the occurrence of the index primary end point and up to 30 days postprocedure. Other secondary end points included the following major adverse events: major bleeding, total death, cardiac death, vascular complications, including AV fistula and pseudoaneurysm, stroke (hemorrhagic or embolic), and myocardial infarction. Demographic, clinical, and procedural angiographic variables were collected (Table 1).

Major bleeding was defined as a drop of 3 units of hemoglobin or transfusion of 2 units of blood with a clear
Table I Descriptive analysis

\begin{tabular}{|c|c|c|c|}
\hline Baseline variables & $\mathbf{n}$ & Mean \pm SD & \\
\hline Age (years) & 779 & $65.6 \pm 12.2$ & \\
\hline \multicolumn{4}{|l|}{ Body mass index $\left(\mathrm{kg} / \mathrm{m}^{2}\right)$} \\
\hline Male & 486 & $31.2 \pm 6.5$ & \\
\hline Female & 293 & $31.3 \pm 7.7$ & \\
\hline \multicolumn{4}{|l|}{ Creatinine clearance $(\mathrm{mL} / \mathrm{min})$} \\
\hline Male & 486 & $105.1 \pm 48.7$ & \\
\hline Female & 293 & $82.8 \pm 42.6$ & \\
\hline International normalized ratio & 51 & $1.7 \pm 1.2$ & \\
\hline Activated clotting times (s) & 193 & $259.8 \pm 65.7$ & \\
\hline Procedure time (min) & 778 & $52.1 \pm 49.7$ & \\
\hline Fluoroscopy time (min) & 776 & $15.2 \pm 17.9$ & \\
\hline Contrast used $(\mathrm{mL})$ & 777 & $180.4 \pm 1 \mid 1.5$ & \\
\hline $\begin{array}{l}\text { Systolic blood pressure when sheath } \\
\text { removed }(\mathrm{mmHg})\end{array}$ & 767 & $130.5 \pm 22.3$ & \\
\hline \multirow[t]{2}{*}{ Intraprocedural heparin (units per kg) } & 296 & $94.1 \pm 47$ & \\
\hline & $\mathbf{n}$ & $\mathbf{n}^{\prime}$ & $\%$ \\
\hline Male & 779 & 486 & 62.4 \\
\hline Age $>75$ (years) & 779 & 184 & 23.6 \\
\hline Weight $<60 \mathrm{~kg}$ & 779 & 50 & 6.4 \\
\hline Hyperlipidemia & 779 & 590 & 75.7 \\
\hline Hypertension & 779 & 593 & 76.1 \\
\hline Diabetes mellitus & 779 & 282 & 36.2 \\
\hline History of smoking & 779 & 445 & 57.1 \\
\hline History of heart failure & 779 & 68 & 8.7 \\
\hline History of atrial fibrillation & 779 & 83 & 10.7 \\
\hline History of myocardial infarction & 779 & 145 & 18.6 \\
\hline Systolic blood pressure & 779 & 85 & 10.9 \\
\hline \multicolumn{4}{|l|}{$(>140 / 90 \mathrm{mmHg})$ after sheath is } \\
\hline Sheath size & 802 & & \\
\hline 6 French & & 428 & 53.4 \\
\hline 8 French & & 363 & 45.3 \\
\hline Others & & 11 & 1.3 \\
\hline Method of hemostasis & 802 & & \\
\hline Closure device & & 567 & 70.7 \\
\hline \multicolumn{3}{|l|}{ hemostasis } & 27.3 \\
\hline Manual hemostasis & & 12 & 1.5 \\
\hline Others & & 4 & 0.5 \\
\hline Type of closure device & 802 & & \\
\hline Perclose & & 557 & 69.4 \\
\hline Angioseal & & 221 & 27.6 \\
\hline Others & & 13 & 2.3 \\
\hline Not applicable & & $\mathrm{II}$ & 1.6 \\
\hline Antiplatelet therapy during procedure & 779 & & \\
\hline None & & 19 & 2.4 \\
\hline Mono antiplatelet & & 202 & 25.9 \\
\hline Dual antiplatelet & & 554 & 71.1 \\
\hline Others & & 4 & 0.5 \\
\hline \multicolumn{4}{|l|}{ procedure } \\
\hline Anticoagulated (group A) & & 27 & 3.5 \\
\hline Not anticoagulated (group B) & & 752 & 96.5 \\
\hline $\begin{array}{l}\text { Intraprocedural parenteral } \\
\text { anticoagulation }\end{array}$ & 779 & & \\
\hline None & & 315 & 40.4 \\
\hline
\end{tabular}


Table I (Continued)

\begin{tabular}{llll}
\hline Baseline variables & $\mathbf{n}$ & $\mathbf{n}^{\prime}$ & $\%$ \\
\hline Bivalirudin & & 165 & 21.2 \\
$\quad$ Heparin & & 273 & 35.0 \\
$\quad$ Heparin and bivalirudin & & 19 & 2.4 \\
$\quad$ Gpllb/llla inhibitors and heparin & & 6 & 0.8 \\
$\quad$ Gpllb/llla inhibitors and heparin & 779 & $\mathrm{I}$ & 0.1 \\
$\quad$ and bivalirudin & & & \\
Procedure urgency & 779 & & \\
Elective & & 479 & 61.5 \\
Urgent & & 233 & 29.9 \\
Emergent & & 67 & 8.6 \\
Prolonged procedure time $(>90 \mathrm{~min})$ & 779 & 98 & 12.6 \\
Low hemoglobin $<10$ g per dL & 779 & 27 & 3.5 \\
preprocedure & & & \\
\hline
\end{tabular}

Abbreviation: SD, standard deviation.

source of bleed: intracranial bleed or retroperitoneal bleed. Myocardial infarction was defined as the presence of 2 of the following: rise in troponin and presence of chest pain or ST segment elevation. Clinically relevant nonmajor bleed was defined as the occurrence of a bleed that required an intervention (stopping the OAC or extending hospital stay or admission) without meeting the definition of a major bleed.

\section{Statistical analysis}

Descriptive analysis of all variables was performed using mean \pm standard deviation for continuous variables and percentages for dichotomous variables. Independent samples $t$-test was used for continuous variables and Fisher's exact testing for dichotomous variables. Bivariate analysis was used to compare Group A (anticoagulated) and Group B (not anticoagulated) and the unadjusted differences between subjects who met the 30-day primary composite endpoint versus subject who did not. Binary logistic regression analysis with backward elimination was performed with modeling for gender, low body weight ( $<60 \mathrm{~kg}$ ), preprocedural hemoglobin, creatinine clearance $(\mathrm{CrCl})$, activated clotting time, fluoroscopy time, body mass index (BMI), heparin dose/ weight $(\mathrm{kg})$, prolonged procedure time ( $>90 \mathrm{~min})$, urgency of procedure, group A (vs B), heparin, and bivalirudin. Collinearity existed between prolonged procedure time and fluoroscopy time; prolonged procedure time was selected for modeling. $\mathrm{CrCl}$, activated clotting time, and BMI were transformed using Johnson transformation due to nonnormality. Interactions between variables were explored with no significance. Hosmer-Lemeshow goodness of fit test was used for model determination ( $P$-value $>0.05)$. Minitab 17 and Cytel Studio 11 were used to conduct the analysis.

\section{Results}

\section{Demographic and clinical characteristics}

A total of 779 patients were included in this study (mean age $65.6 \pm 12.2$ years, males $62.4 \%$ ). Of these patients, 27 (3.5\%) patients were in group A. Table 1 describes patients' demographic and clinical characteristics. Notably, 464/779 (59.6\%) underwent an interventional procedure and received intraprocedural anticoagulation with either bivalirudin $(21.2 \%)$ or heparin $(35.0 \%)$ or both $(2.4 \%)$. GpIIb/IIIa inhibitors were rarely used $(0.9 \%)$. Closure devices were used in most patients $(98.0 \%)$, predominantly Perclose $(69.0 \%)$ followed by Angioseal (27.3\%).

\section{Outcomes}

The index primary end point was met in 11/779 (1.4\%) patients. All adverse events at index procedure were seen in $25 / 779$ (3.2\%) patients. These were adjudicated to be definitely or maybe related to access site in $7 / 25(28.0 \%)$ and procedure related in $12 / 25(48.0 \%)$. There was no difference in the primary composite end point at index between group $\mathrm{A}$ $(1 / 27[3.7 \%])$ and group $\mathrm{B}(10 / 752[1.3 \%] ; P=0.3155)$. There was also no difference in the total adverse events at index between group A (3/27 [3.7\%]) and group B (22/752 [2.9\%]; $P=0.6391$ ).

The 30-day primary composite end point (Table 2) was met in 18/779 (2.3\%) patients. All adverse events at the 30-day postprocedure were seen in 43/779 (5.5\%) patients. These were adjudicated to be definitely or maybe related to access site in $7 / 42(17.9 \%)$ and procedure related in 14/42 (48.3\%). There was no difference in the 30-day primary composite end point between group A (2/27 [7.4\%]) and group B (16/752 [2.1\%]; $P=0.1313)$. There was also no difference in the total adverse events at 30 days between group A (4/27 [14.8\%]) and group B (39/752 [5.2\%]; $P=1.000)$.

In bivariate analysis (Table 3 ), the 30 -day primary end point was significantly associated with female gender ( $P=0.0481)$, weight $<60 \mathrm{~kg}(P=0.0040)$, low hemoglobin at baseline $(P=0.0410)$, reduced $\mathrm{CrCl}(P=0.0001)$, high activated clotting time (ACT) $(P=0.0150)$, high intraprocedural heparin dose (units per kg; $P=0.0110)$, and high BMI $(P=0.0040)$ but not group A versus group B. There was also no association between the type of coronary procedure done (cardiac catheterization vs intervention) and the primary adverse event at the time of the procedure $(0.95 \%$ and $1.72 \%$, respectively, $P=0.5393)$ or at 1 month $(P=1.000)$. However, patients who underwent an intervention in group $\mathrm{B}$ had a higher primary adverse event at 1 month when compared to cardiac catheterization patients in group B. 
Table 2 Adverse events in orally anticoagulated (group A) versus nonanticoagulated (group B) patients

\begin{tabular}{|c|c|c|c|c|}
\hline Adverse events & Group A & Group B & Total & $P$-value \\
\hline Index adverse events & $\mathrm{n}=27$ & $\mathrm{n}=752$ & $\mathrm{n}=779$ & \\
\hline Major bleeding & I & 7 & 8 & \\
\hline Clinically relevant nonmajor bleed & 0 & 3 & 3 & \\
\hline Noncardiovascular death & 0 & 3 & 3 & \\
\hline Cardiac death & 2 & 6 & 8 & \\
\hline Vascular complications & 0 & 3 & 3 & \\
\hline Total adverse events, $\mathrm{n}(\%)$ & $3(11.1 \%)$ & $22(2.9 \%)$ & $25(3.2 \%)$ & 0.7500 \\
\hline Adverse events maybe or definitely related to access site & & & $7 / 25(28 \%)$ & \\
\hline Adverse events maybe or definitely related to procedure & & & $12 / 25(48 \%)$ & \\
\hline $\begin{array}{l}\text { Primary composite endpoint at index, (major bleeding, } \\
\text { vascular complications, and cardiac death), } \mathrm{n}(\%)\end{array}$ & I (3.7\%) & $10(1.3 \%)$ & $\mathrm{II}(1.4 \%)$ & 0.3200 \\
\hline 30-day adverse events & $\mathrm{n}=27$ & $\mathrm{n}=752$ & $\mathrm{n}=779$ & \\
\hline Major bleeding & 2 & 10 & 12 & \\
\hline Clinically relevant nonmajor bleed & 0 & 3 & 3 & \\
\hline Noncardiovascular death & 0 & 3 & 3 & \\
\hline Cardiac death & 2 & 7 & 9 & \\
\hline Stroke & 0 & 3 & 3 & \\
\hline Myocardial infarction & 0 & 7 & 7 & \\
\hline Vascular complications & 0 & 6 & 6 & \\
\hline Total adverse events, $\mathrm{n}(\%)$ & $4(14.8 \%)$ & $39(5.2 \%)$ & $43(5.5 \%)$ & 0.6300 \\
\hline Adverse events maybe or definitely related to access site & & & $9 / 43(20.9 \%)$ & \\
\hline Adverse events maybe or definitely related to procedure & & & $15 / 43(34.9 \%)$ & \\
\hline $\begin{array}{l}\text { 30-day primary composite end point, (major bleeding, } \\
\text { vascular complications, and cardiac death), n (\%) }\end{array}$ & $2(7.4 \%)$ & $16(2.1 \%)$ & $18(2.3 \%)$ & 0.1300 \\
\hline
\end{tabular}

Multivariable analysis (Table 4) using various models showed that a low $\mathrm{CrCl}$ (odds ratio [OR] 0.56, $P=0.0200$ ) and underweight patients $(<60 \mathrm{~kg}$; OR 3.94, $P=0.0300)$ were independent predictors of the 30 -day primary composite end point but not oral anticoagulation $(P=0.15)$. On the other hand, a low hemoglobin preprocedure (OR 0.65, $P=0.0140)$, emergent/urgent procedure (OR 8.9, $P<0.0000)$, a prolonged procedure time (OR 12.08, $P=0.0010)$, and

Table 3 Unadjusted differences between subjects who met the 30-day primary composite endpoint versus subjects who did not

\begin{tabular}{|c|c|c|c|c|}
\hline Variables & Total & No end point met & 30-day primary end point met & $P$-value \\
\hline Gender & $\mathrm{n}=779$ & & & \\
\hline Female & 293 & $282(36.5 \%)$ & II (6I.1\%) & $0.048 \mathrm{I}$ \\
\hline Male & 486 & 479 (6I.5\%) & 7 (38.9\%) & \\
\hline Weight & $\mathrm{n}=779$ & & & \\
\hline$<60 \mathrm{~kg}$ & 729 & $716(91.9 \%)$ & $13(72.2 \%)$ & 0.0040 \\
\hline$\geq 60 \mathrm{~kg}$ & 50 & $45(5.8 \%)$ & $5(27.8 \%)$ & \\
\hline Access site-related complications & $n=43$ & & & \\
\hline Unrelated & 34 & $24(92.3 \%)$ & $10(58.8 \%)$ & 0.0115 \\
\hline Maybe and definite & 9 & $2(7.7 \%)$ & $7(4 I .2 \%)$ & \\
\hline Procedure-related complications & $n=42$ & & & \\
\hline Unrelated & 26 & $20(83.3 \%)$ & $6(33.3 \%)$ & 0.0014 \\
\hline Maybe and definite & 16 & $4(16.7 \%)$ & $12(66.7 \%)$ & \\
\hline Coronary procedure & $n=779$ & & & \\
\hline Cardiac catheterization & 315 & 309 (40.6\%) & $6(33.3 \%)$ & 0.6318 \\
\hline Cardiac intervention & 464 & $452(59.4 \%)$ & $12(66.7 \%)$ & \\
\hline Preprocedure hemoglobin $(g / d L)$ & 747 & 729 & 18 & 0.0410 \\
\hline Creatinine clearance $(\mathrm{mL} / \mathrm{min})$ & 771 & 753 & 18 & 0.0001 \\
\hline Activated clotting time $(\mathrm{s})$ & 193 & 185 & 8 & 0.0150 \\
\hline Fluoroscopy time (min) & 776 & 758 & 18 & 0.0230 \\
\hline Body mass index $\left(\mathrm{kg} / \mathrm{m}^{2}\right)$ & 779 & 761 & 18 & 0.0040 \\
\hline Heparin/weight (units per kg) & 296 & 285 & 11 & 0.0110 \\
\hline
\end{tabular}


Table 4 Logistic regression analysis for predictors of adverse events

\begin{tabular}{|c|c|c|c|}
\hline Variables & $\begin{array}{l}\text { Odds } \\
\text { ratio } \\
(\text { OR) }\end{array}$ & $\begin{array}{l}95 \% \text { OR } \\
\text { confidence } \\
\text { interval }\end{array}$ & $P$-value \\
\hline \multicolumn{4}{|c|}{ Analysis for predictors of 30-day primary composite end point } \\
\hline Transformed creatinine clearance & 0.56 & $0.33,0.92$ & 0.0200 \\
\hline Weight $<60$ (vs $>60)$ kg & 3.94 & $1.26,12.37$ & 0.0300 \\
\hline Group A (vs B) & 2.12 & $0.80,17.93$ & 0.1500 \\
\hline \multicolumn{4}{|c|}{ Analysis for predictors of 30-day composite primary and secondary events } \\
\hline $\begin{array}{l}\text { Transformed hemoglobin } \\
\text { preprocedure }\end{array}$ & 0.65 & $0.46,0.92$ & 0.0140 \\
\hline Group A (vs B) & 3.82 & $1.15,12.68$ & 0.0500 \\
\hline $\begin{array}{l}\text { Urgency of procedure } \\
\text { (emergent/urgent vs elective) }\end{array}$ & 8.9 & $3.61,21.91$ & $<0.0000$ \\
\hline Procedure time & 12.08 & $3.29,44.30$ & 0.0010 \\
\hline
\end{tabular}

orally anticoagulated patients (OR 3.82, $P=0.0500$ ) were independent predictors of the 30-day composite primary and secondary end points.

\section{Discussion}

Adverse events during index coronary angiography occurred in $3.7 \%$ of patients. This is within the reported range of access site complications. In multivariate analysis, irrespective of the intraprocedural anticoagulant, patients with uninterrupted anticoagulation with OAC did not have an increase in the composite primary end point of major bleeding, vascular complications (AV fistula or pseudoaneurysm), or cardiovascular death during their index hospitalization and up to 30 days when compared to patients who were not anticoagulated with OAC.

These data, however, do not apply to patients who receive lytic therapy (as none of our patients had received a thrombolytic) or GPIIb/IIIa inhibitors ( $<1 \%$ of patients in our cohort). ${ }^{11}$ Furthermore, these data are in the setting of the majority of patients receiving a closure device and, therefore, cannot be extended to those who undergo hemostasis with manual compression. There are conflicting data on the value of vascular closure devices in reducing complications postfemoral arterial access in patients undergoing cardiac procedures. ${ }^{12-15}$ Recent data, however, seem to favor closure devices in reducing complications postcardiac diagnostic or interventional procedures. ${ }^{14,15}$ Finally, no radial approach patients were included in this study (limited use of radial in our laboratory). Recent studies have shown that both radial and femoral approaches were safe after percutaneous coronary intervention but a radial approach had less vascular complications. ${ }^{2,16}$ On the other hand, a femoral approach with vascular closure device (Angioseal) was noninferior to a radial approach in reducing postcardiac procedure complications. ${ }^{17}$ However, studies have shown that patients with uninterrupted warfarin undergoing radial approach had less vascular complications. ${ }^{18,19}$

In this study, univariate analysis indicated that the higher the units per kilogram of unfractionated heparin administered intraprocedurally, the higher the primary composite adverse end points. Intraprocedural antithrombotic therapy has been shown to increase the risk of vascular complications in patients who are on warfarin irrespective of the degree of anticoagulation. ${ }^{20}$ Multivariate analysis, however, showed that intraprocedural heparin, when adjusted for $\mathrm{CrCl}$ and underweight patients $(<60 \mathrm{~kg})$, did not predict adverse events. The presence of renal failure is a strong predictor of adverse events postcardiac intervention. ${ }^{21,22}$ In a study of 8,521 patients evaluating the relationship between glomerular filtration rate (GFR) and all-cause mortality, there was a decline in survival postcatheterization that correlated with a decline in GFR. In this study, for every 10 -unit decrease in GFR, there was $\sim 17.2 \%$ relative increase in mortality risk. This is consistent with the findings in this study that showed that an increase in $\mathrm{CrCl}$ reduces the likelihood of occurrence of the 30-day composite end points of major bleeding, vascular complications, and cardiovascular death (OR 0.56). Also, several studies have shown that a high or low BMI correlate with vascular complications. ${ }^{3-5,7}$ In our study, a low weight of $<60 \mathrm{~kg}$ was an independent predictor of complications in orally anticoagulated patients.

A lower preprocedural hemoglobin, $\mathrm{OAC}$, a longer procedure time, and an urgent/emergent procedure independently predicted the combined 30-day adverse events (major bleeding, cardiac and noncardiac death, stroke, myocardial infarction, and vascular complications). These events are driven by death, myocardial infarction, and stroke and likely reflect a high-risk patient population with more unstable symptoms and requiring prolonged procedures. ${ }^{23,24}$

\section{Limitation of the study}

This is a retrospective study and therefore selection bias cannot be ruled out. This, however, was addressed by including all consecutive patients with the exception of excluding those with bilateral CFA and non-CFA access sites (small number of patients in our center). Therefore, data in this study do not apply to radial procedures. Radial access appears to be safe in patients actively on anticoagulation and is now becoming more widely adopted in the US. Finally, this study needs to be verified in a larger registry of patients on anticoagulation as the overall number of anticoagulated patients in this study is relatively small and with low number of patients reaching end points. 


\section{Conclusion}

Independent predictors of the combined end points of major bleeding, vascular complications, or cardiovascular death at index or up to 30 days in patients undergoing coronary procedures are low weight $(<60 \mathrm{~kg})$ and renal insufficiency but not OAC. These conclusions are limited to patients undergoing femoral vascular access and not receiving GPIIb/IIIa inhibitors or lytic therapy.

\section{Disclosure}

The authors report no conflicts of interest in this work.

\section{References}

1. Asrar U, Haq M, Tsay IM, et al. Prevalence and outcomes of transradial access for percutaneous coronary intervention in contemporary practice. Int J Cardiol. 2016;221:264-268.

2. Feldman DN, Swaminathan RV, Kaltenbach LA, et al. Adoption of radial access and comparison of outcomes to femoral access in percutaneous coronary intervention: an updated report from the national cardiovascular data registry (2007-2012). Circulation. 2013;127(23):2295-2306.

3. Piper WD, Malenka DJ, Ryan TJ Jr, et al; Northern New England Cardiovascular Disease Study Group. Predicting vascular complications in percutaneous coronary interventions. Am Heart J. 2003;145(6): 1022-1029.

4. Sherev DA, Shaw RE, Brent BN. Angiographic predictors of femoral access site complications: implication for planned percutaneous coronary intervention. Catheter Cardiovasc Interv. 2005;65(2):196-202.

5. Chandrasekar B, Doucet S, Bilodeau L, et al. Complications of cardiac catheterization in the current era: a single-center experience. Catheter Cardiovasc Interv. 2001;52(3):289-295.

6. Yatskar L, Selzer F, Feit F, et al. Access site hematoma requiring blood transfusion predicts mortality in patients undergoing percutaneous coronary intervention: data from the National Heart, Lung, and Blood Institute Dynamic Registry. Catheter Cardiovasc Interv. 2007;69(7): 961-966.

7. Trimarchi S, Smith DE, Share D, et al; BMC2 Registry. Retroperitoneal hematoma after percutaneous coronary intervention: prevalence, risk factors, management, outcomes, and predictors of mortality: a report from the BMC2 (Blue Cross Blue Shield of Michigan Cardiovascular Consortium) registry. JACC Cardiovasc Interv. 2010;3(8):845-850.

8. El-Jack SS, Ruygrok PN, Webster MW, et al. Effectiveness of manual pressure hemostasis following transfemoral coronary angiography in patients on therapeutic warfarin anticoagulation. Am J Cardiol. 2006; 97(4):485.

9. Deftereos S, Tsounis D, Giannopoulos G, et al. Oral IIa and Xa inhibitors for prevention of stroke in atrial fibrillation: clinical studies and regulatory considerations. Curr Clin Pharmacol. 2012;7(3):166-174.

10. Jamula E, Lloyd NS, Schwalm JD, Airaksinen KE, Douketis JD. Safety of uninterrupted anticoagulation in patients requiring elective coronary angiography with or without percutaneous coronary intervention: a systematic review and metaanalysis. Chest. 2010;138(4):840-847.
11. Lefkovits J, Plow EF, Topol EJ. Platelet glycoprotein IIb/IIIa receptors in cardiovascular medicine. N Engl J Med. 1995;332(23):1553-1559.

12. Koreny M, Riedmüller E, Nikfardjam M, Siostrzonek P, Müllner M. Arterial puncture closing devices compared with standard manual compression after cardiac catheterization: systematic review and metaanalysis. JAMA. 2004;291(3):350.

13. Nikolsky E, Mehran R, Halkin A, et al. Vascular complications associated with arteriotomy closure devices in patients undergoing percutaneous coronary procedures: a meta-analysis. J Am Coll Cardiol. 2004;44(6):1200.

14. Arora N, Matheny ME, Sepke C, Resnic FS. A propensity analysis of the risk of vascular complications after cardiac catheterization procedures with the use of vascular closure devices. Am Heart J. 2007;153(4): 606-611.

15. Tavris DR, Wang Y, Jacobs S, et al. Bleeding and vascular complications at the femoral access site following percutaneous coronary intervention (PCI): an evaluation of hemostasis strategies. J Invasive Cardiol. 2012;24(7):328-334.

16. Jolly SS, Yusuf S, Cairns J, et al. Radial versus femoral access for coronary angiography and intervention in patients with acute coronary syndromes (RIVAL): a randomized, parallel group, multicentre trial. Lancet. 2011;23:1409-1420.

17. Andrade PB, Mattos LA, Rinaldi FS, et al. Comparison of a vascular closure device versus the radial approach to reduce access site complications in non-ST-segment elevation acute coronary syndrome patients: the angio-seal versus the radial approach in acute coronary syndrome trial. Catheter Cardiovasc Interv. Epub 2016 Aug 12:doi: $10.1002 / \mathrm{ccd} .26689$

18. Baker NC, O'Connell EW, Htun WW, et al. Safety of coronary angiography and percutaneous coronary intervention via the radial versus femoral route in patients on uninterrupted oral anticoagulation with warfarin. Am Heart J. 2014;168(4):537-544.

19. Ziakas AG, Koskinas KC, Gavrilidis S, et al. Radial versus femoral access for orally anticoagulated patients. Catheter Cardiovasc Interv. 2010; 76(4):493-499.

20. Subherwal S, Peterson ED, Chen AY, et al. Admission international normalized ratio levels, early treatment strategies, and major bleeding risk among non-ST-segment-elevation myocardial infarction patients on home warfarin therapy: insights from the National Cardiovascular Data Registry. Circulation. 2012;125(11):1414-1423.

21. Gruberg L, Mintz GS, Mehran R, et al. The prognostic implications of further renal function deterioration within $48 \mathrm{~h}$ of interventional coronary procedures in patients with pre-existent chronic renal insufficiency. J Am Coll Cardiol. 2000;36(5):1542.

22. Hemmelgarn BR, Southern DA, Humphries KH, et al; Alberta Provincial Project for Outcomes Assessment in Coronary Heart Disease (APPROACH) Investigators. Refined characterization of the association between kidney function and mortality in patients undergoing cardiac catheterization. Eur Heart J. 2006;27(10):1191.

23. Wyman RM, Safian RD, Portway V, Skillman JJ, McKay RG, Baim DS. Current complications of diagnostic and therapeutic cardiac catheterization. J Am Coll Cardiol. 1988;12(6):1400.

24. King KM, Ghali WA, Faris PD, et al. Sex differences in outcomes after cardiac catheterization: effect modification by treatment strategy and time. JAMA. 2004;291(10):1220.
Therapeutics and Clinical Risk Management

\section{Publish your work in this journal}

Therapeutics and Clinical Risk Management is an international, peerreviewed journal of clinical therapeutics and risk management, focusing on concise rapid reporting of clinical studies in all therapeutic areas, outcomes, safety, and programs for the effective, safe, and sustained use of medicines. This journal is indexed on PubMed Central, CAS,

\section{Dovepress}

EMBase, Scopus and the Elsevier Bibliographic databases. The manuscript management system is completely online and includes a very quick and fair peer-review system, which is all easy to use. Visit http://www.dovepress.com/testimonials.php to read real quotes from published authors. 